\title{
Technological and nutritional aspects of gluten-free pasta based on chickpea flour and tiger nut flour
}

\author{
Martín-Esparza. M. E. ${ }^{a^{*}}$; Bressi. G. B. ${ }^{\text {a }}$ Raga. A. ${ }^{\text {a }}$ Albors. A. ${ }^{\text {a }}$ \\ a Institute of Food Engineering for Development. Food Technology Department. Universitat \\ Politècnica de València. Valencia. Spain.
}

*E-mail of the corresponding author: eesparza@tal.upv.es

\begin{abstract}
Gluten-free (GF) dry egg pappardelle was prepared with tigernut flour (50\%), chickpea flour (50\%) and pregelatinized $\operatorname{TNF}(0,5,10 \%)$, and compared to plain pasta (100\% durum wheat semolina). The GF pasta may have a significant higher content of insoluble fibre, minerals and fat rich in oleic acid and a similar protein content. It was not found any clear relationship between the flour functional properties and its proximate composition. The use of PG did not imply an improvement on the firmness but did provide some continuity to the pasta structure.
\end{abstract}

Keywords: Gluten-free pasta, tigernut flour, chickpea flour, texture, cooking properties. 


\section{Introduction}

The celiac disease is one of the most common food induced disorders worldwide with an estimated mean prevalence of $1 \%$ of the total population [1]. To date, the only efficacious treatment for celiac disease affected patients is a gluten-free diet. However, many GF products based on cereals exhibit lower nutritional quality [2] and, not less important, higher glycemic index [3] than their gluten containing counterparts. Since pasta is one of the products that is most demanded by people with celiac disease [4], the aim of this study was to evaluate the chemical composition, the cooking characteristics and microstructure of GF pappardelle prepared with tiger nut and chickpea flours. Chickpea flour is a source of proteins, carbohydrates, dietetic fibre and oligosaccharides. Tigernut flour is a rich source of dietary fibre, high-quality fatty acid profile oil, which is similar to olive and hazelnut oil, minerals and vitamins such as phosphorus, potassium, iron and calcium, as well as vitamins $\mathrm{E}$ and $\mathrm{C}$. Therefore, the combination of these flours may lead to an improved nutritional value of the resulting pasta, with a high fibre content and a lower glycaemic index. Despite the great efforts made in the last few decades to produce GF pasta with sensory characteristics similar to durumwheat products (good texture, minimum cooking losses, surface resistance to disintegration, without surface stickiness), the GF pasta currently on the market is still far from what the consumer is looking for [4]. The role of gluten could be replaced by choosing suitable formulations to achieve the desirable quality attributes and also making the dough easy to handle under industrial conditions [5]. Frequently, GF products are formulated using sintetic additives to improve the textural characteristics. Nowadays, both industry and consumer preference is to use other additives from natural sources. Previous studies have demonstrated the positive impact that the use of pregelatinized starch from rice [6] or cassava [7] has on the GF pasta texture. Pregelatinized flour can act as a binder [8] that may lead to the development of a viscoelastic and compact dough, which may contribute to obtain suitable palatability and textural characteristics on the pasta products. In this sense, this work assess the feasibility of replacing chickpea flour by tiger nut pregelatinized flour to improve the cooking behavior and final textural characteristics of dry GF pappardelle based on tiger nut and chickpea flours.

\section{Materials and Methods}

\subsection{Raw materials and characterisation}

Commercial durum wheat semolina -DWS- (Harinas Villamayor. S.A., Huesca. Spain). tiger nut flour-TNF-(Tigernuts Traders S.L., Valencia. Spain) and chickpea flour (CP) were used. Fresh eggs, CP and mineral water were purchased in a local market. PG was obtained by hot treatment $\left(80^{\circ} \mathrm{C}, 20 \mathrm{~min}, 1: 7.5 \mathrm{~g} / \mathrm{mL}\right.$ deionized water) followed by drying $\left(40^{\circ} \mathrm{C}, 24 \mathrm{~h}\right)$ and grinding. DWS, TNF, CP and PG were analysed for their water, protein, 
fat and ash contents according to the American Association of Cereal Chemists' approved methods [9] and for their total, soluble and insoluble fibre, amylose/amylopectin ratio and damaged starch according to the corresponding Megazyme methods K-TDFR, K-SDAM and K-AMYL (Megazyme Ltd., Ireland). Digestible carbohydrates were determined by difference (100 - percentage of estimated proximate chemical composition). The particle size distribution (PSD) of DWS, TNF, CP, PG and their mixtures (TNFCPPG0, TNFCPPG5, TNFPPG10) was determined by using a MasterSizer® Laser Diffraction Particle Size Analyser (Malvern Instrument Ltd., Malvern, England). equipped with a PS 65 (dry sample). For each sample, 10-20 g of flour mixture was used. Size distribution was quantified as the relative volume of particles in size bands, presented as size distribution curves (Malvern MasterSizer Micro software v 5.40). The PSD parameters recorded included mean particle diameter/volume mean diameter $(\mathrm{D}[4.3])$ and span value (measurement of the width of the size distribution). The functional properties of DWS, TNF, CP, PG and their blends (TNFCPPG0, TNFCPPG5, TNFPPG10). were determined as follows. The water-holding capacity (WHC) was determined by using the modified methods from [10] and [11]. The fat adsorption capacity (FAC) was determined according to [12]. Each analysis was made in triplicate.

\subsection{Pasta preparation}

The $\mathrm{S}$ formulation, used as the control sample, was obtained by mixing durum wheat semolina $(72 \% \mathrm{w} / \mathrm{w})$, fresh egg $(13 \% \mathrm{w} / \mathrm{w})$ and water $(15 \% \mathrm{w} / \mathrm{w})$. For the GF formulations, TNF and CP were used at 50/50 weight $(76 \% \mathrm{w} / \mathrm{w})$ and mixed with fresh egg $(13 \% \mathrm{w} / \mathrm{w})$ and water $(11 \% \mathrm{w} / \mathrm{w})$. Three GF formulations were assessed, considering three levels for chickpea replacement by pregelatinized $\operatorname{TNF}(0,5$ and $10 \% \mathrm{w} / \mathrm{w}$, named henceforth as TNFCPPG0, TNFCPPG5 and TNFCPPG10 respectively). All raw materials were mixed and kneaded in an electric cooking device (Thermomix TM-31, Vorwerk Spain M.S.L., S.C., Madrid). The dried (CP/TNF/PG) and liquid (egg/water) components were separately blended and then kneaded together (10 min for $\mathrm{S}$ and $20 \mathrm{~min}$ each for GF pasta) with a rest period in between. The resulting doughs were rested for $20 \mathrm{~min}$ at $4{ }^{\circ} \mathrm{C}$ inside a plastic bag in order to enable sample relaxation. Afterwards, the fresh pasta sheets $(1.0 \pm 0.03 \mathrm{~mm}$ thick $)$ were formed by using a domestic pasta making machine (Simplex SP150, Imperia, Italy) coupled with a specific motor (A2500, Imperia, Italy). The pappardelle (4.4 cm width) were obtained by using the Duplex reginette 12/44 mm device (Imperia, Italy). Samples of $7 \mathrm{~cm}$ $\pm 0.03 \mathrm{~mm}$ length were then dried for $5.5 \mathrm{~h}$ (SCC 62, Rationel, Germany) under controlled temperature $\left(55^{\circ} \mathrm{C}\right)$ and relative humidity $(60 \%)$ conditions (until the pasta reached a water content of $10-12 \%$ (similar to that of dried commercial pasta). Once dried, the pappardelle were packed in vacuum bags and stored at $4^{\circ} \mathrm{C}$ temperature until further analysis. 


\subsection{Uncooked pasta structure}

FESEM (ULTRA 55, Carl Zeiss AG. Oberkochen. Germany) was used in order to observe the microstructure of dry GF pappardelle (TNFCPPG0, TNFCPPG5 and TNFCPPG10). The samples (cross-section) were fixed on copper stubs, platinum coated and observed using an accelerating voltage of $2 \mathrm{kV}$.

\subsection{Pasta cooking}

Dried pappardelle $(25 \mathrm{~g})$ was cooked in $300 \mathrm{ml}$ deionised water $\left(98^{\circ} \mathrm{C}\right)$ according to the American Association of Cereal Chemists' approved method 16-50 [9]. To avoid evaporation losses and maintain the $90 \%$ of the initial volume, the flask was partially covered and boiling water was added during cooking. Once reached the optimal cooking time ( 9 min for $\mathrm{S}$ and $5 \mathrm{~min}$ for the rest ), the pappardelle were removed from the flasks and the cooking process was immediately stopped with $50 \mathrm{ml}$ of cold deionised water. Finally, the pappardelle were drained for $2 \mathrm{~min}$ and immediately analysed for its firmness and cooking properties. Cooking trial was made in duplicate for each pasta formulation.

\subsection{Cooking properties and cooked pasta firmness}

The water absorption index -WAI- $(\mathrm{g} / \mathrm{g})$ was calculated from the mass gain and the increase in water content after cooking. The water content in dry and cooked pasta was determined according to the AACC 44-40 method [9]. Cooking loss -\%CL- (g/100 g) is the amount of solid substance lost to cooking water and it was determined according to the AACC-approved method 16-50 [9]. The swelling index -SI- was expressed as the relative volume changes $\left(\mathrm{cm}^{3} / \mathrm{cm}^{3}\right)$ between the uncooked and cooked pasta. The measurements of the pappardelle (thickness, width and length) were determined with a caliper (PCE-DCP 200N, PCE Ibérica S.L., Albacete, Spain). A TA.XT2 Texture Analyser (Stable Micro Systems. Godalming. Surrey. UK) was used to perform the AACC method 16-50 [9] at a rate of $0.17 \mathrm{~mm} / \mathrm{s}$ until total sample deformation. Each analysis was made in triplicate for each pasta formulation.

\subsection{Statistical analysis}

Analysis of variance (ANOVA) was carried out by using Statgraphics Centurion XVI software version 16.1.17 (StatPoint Technologies. Inc., Warrenton, VA) The significance level was $\mathrm{p}=0.05$ in all cases.

\section{Results and discussion}

\subsection{Characterization of raw solid materials}

The chemical composition of the solid raw materials (DWS, TNF, CP and PG) are shown in Table 1. As expected, the TNF and CP fibre (specially insoluble) content was much higher than that of DWS. Fat content was also much higher for TNF, while the highest protein 
content was obtained for CP. On the other hand. the highest amount of digestible carbohydrates was obtained for DWS, followed by TNF and CP, being the amylose content lower for TNF. Damaged starch was significantly higher for PG.

Table 1. Proximate chemical composition of solid raw materials (g/100 g). Mean values of three replicates (standard deviation).

\begin{tabular}{lcccc}
\hline & DWS & TNF & CP & PG \\
\hline Water & $13.43(0.13)^{\mathrm{b}}$ & $12(0.7)^{\mathrm{c}}$ & $11.48(0.95)^{\mathrm{c}}$ & $16.8(0.3)^{\mathrm{a}}$ \\
Protein & $13.18(0.7)^{\mathrm{b}}$ & $3.7(0.2)^{\mathrm{c}}$ & $23.7(0.07)^{\mathrm{a}}$ & - \\
Fat & $0.9(0.05)^{\mathrm{d}}$ & $21.44(0.06)^{\mathrm{b}}$ & $4.31(0.03)^{\mathrm{c}}$ & $23.59(0.04)^{\mathrm{a}}$ \\
Ash & $0.27(0.03)^{\mathrm{c}}$ & $2.29(0.07)^{\mathrm{b}}$ & $3.298(0.007)^{\mathrm{a}}$ & $2.32(0.03)^{\mathrm{b}}$ \\
Fiber & & & & \\
$\quad$-Soluble & $2.99(0.13)^{\mathrm{b}}$ & $3.5(1.3)^{\mathrm{b}}$ & $6(3)^{\mathrm{ab}}$ & $7.5(0.8)^{\mathrm{a}}$ \\
$\quad$-Insoluble & $7(3)^{\mathrm{c}}$ & $16.6(0.8)^{\mathrm{b}}$ & $24(0.6)^{\mathrm{a}}$ & $24(4)^{\mathrm{a}}$ \\
$\quad$-Total & $9.1(0.4)^{\mathrm{c}}$ & $20(2)^{\mathrm{b}}$ & $30(3)^{\mathrm{a}}$ & $32(3)^{\mathrm{a}}$ \\
DC* & $63.3(0.2)^{\mathrm{a}}$ & $40(2)^{\mathrm{b}}$ & $28(4)^{\mathrm{c}}$ & - \\
$\quad$ Amilose (\%) & $27.2(1.4)^{\mathrm{a}}$ & $17(2)^{\mathrm{b}}$ & $28(2)^{\mathrm{a}}$ & - \\
Damaged starch & $3.31(0.12)^{\mathrm{b}}$ & $0.622(0.109)^{\mathrm{c}}$ & $0.6717(0.005)^{\mathrm{c}}$ & $20(3)^{\mathrm{a}}$ \\
\hline
\end{tabular}

Means with different letters in the same row indicate significant differences $(\mathrm{p}<0.05)$.

* Digestible carbohydrates calculated by difference

Concerning PG, its chemical composition was near to that of TNF, except for the fibre (due to a higher extraction capacity) and the damaged starch (due to gelatinization) contents. These results suggest that the use of TNF and $\mathrm{CP}$ at $50 \% \mathrm{w} / \mathrm{w}$ may allow to obtain GF pasta with a similar protein content and a higher presence of fibre, minerals and fat than the DWS formulation. It can be observed in Table 2 that the average particle size (expressed as the mean diameter of the equivalent volume) was significantly lower for $\mathrm{CP}$, followed by TNF and DWS. Fibre hydration and starch gelatinization could be the responsible for the significantly higher particle size of PG. Furthermore, the uniformity in the particle size distribution (span) was higher in DWS (from industrial milling) and PG (obtained after grinding). The greater presence of fibre in TNF (20 (2)\%) and CP (30 (3)\%) compared to $9.1(0.4) \%$ in DWS ) -with a much higher insoluble/soluble ratio- (16.6/3.5\% in TNF and $24 / 6 \%$ in CP compared to $7 / 2.99 \%$ in DWS) could be responsible for the greater heterogeneity in TNF (span 2.39) or CP (span 6.9). Water holding capacity (WHC) reports the ability of a protein matrix to absorb and retain bound, hydrodynamic, capillary and physically entrapped water against gravity. The results show a significant lower value for DWS, which can be attributed to the higher fibre content of TNF and CP and the smaller particle size of TNF and CP, which implies a larger surface area available for water absorption [13]. The highest WHC obtained for PG may be due to the its higher damaged starch content; however, no effect was observed on the mixture when PG was added at 5 
and $10 \%$. The fat absorption capacity (FAC) is attributed to the ability of proteins to bind lipids. Only TNF presents a significant higher value of this parameter.

Table 2. Particle size distribution and Functional properties of solid raw materials and their blends. Mean values of three replicates (standard deviation).

\begin{tabular}{ccccc}
\hline Sample & D $[4.3](\mu \mathbf{m})$ & Span & $\begin{array}{c}\text { WHC (g water/g } \\
\text { flour) }\end{array}$ & $\begin{array}{c}\text { FAC }(\mathbf{g} \text { fat/g } \\
\text { flour) }\end{array}$ \\
\hline DWS & $317.9(1.8)^{\mathrm{b}}$ & $1.156(0.012)^{\mathrm{f}}$ & $0.9(0.07)^{\mathrm{d}}$ & $1.2(0.2)^{\mathrm{b}}$ \\
TNF & $221(4)^{\mathrm{d}}$ & $2.39(0.03)^{\mathrm{c}}$ & $2.1(0.2)^{\mathrm{b}}$ & $1.749(0.104)^{\mathrm{a}}$ \\
CP & $141(12)^{\mathrm{f}}$ & $6.9(0.9)^{\mathrm{a}}$ & $1.98(0.2)^{\mathrm{b}}$ & $1.25(0.04)^{\mathrm{b}}$ \\
PG & $632(8)^{\mathrm{a}}$ & $1.77(0.03)^{\mathrm{d}}$ & $2.9(0.2)^{\mathrm{a}}$ & $1.31(0.06)^{\mathrm{b}}$ \\
TNFCPPG0 & $225(2)^{\mathrm{d}}$ & $2.382(0.008)^{\mathrm{c}}$ & $1.591(0.112)^{\mathrm{c}}$ & $1.29(0.02)^{\mathrm{b}}$ \\
TNFCPPG5 & $191.3(0.9)^{\mathrm{e}}$ & $3.07(0.05)^{\mathrm{b}}$ & $1.586(0.012)^{\mathrm{c}}$ & $1.3(0.03)^{\mathrm{b}}$ \\
TNFCPPG10 & $232(3)^{\mathrm{c}}$ & $2.22(0.03)^{\mathrm{c}}$ & $1.6(0.4)^{\mathrm{c}}$ & $1.19(0.06)^{\mathrm{b}}$ \\
\hline
\end{tabular}

Means with different letters in the same column indicate significant differences $(\mathrm{p}<0.05)$.

\subsection{Cooking properties and cooked pasta firmness}

Cooking loss, a measure of the amount of solids lost in the cooking water, is considered to be an important indicator of pasta quality [14]. As reported by [15], cooking losses for GF pasta can reach 20-25\% values as compared to those of a wheat semolina pasta due to the better weaker gluten network in which swelled starch granules are worse entrapped. Obtained values in this work (Table 3) are similar to those obtained for other GF pasta based on legume flours [16] and quinoa [17]. No significant differences could be observed for WAI and SI with the percentage of PG used, but both parameters were significant higher for control samples.

Table 3. Cooking properties of pasta formulations. Mean values (standard deviation).

\begin{tabular}{l|llcc}
\hline Sample & WAI $(\mathbf{g} / \mathbf{g})$ & $\mathbf{\%} \mathbf{C L}$ & SI & F $(\mathbf{N})$ \\
\hline $\mathrm{S}$ & $1.74(0.02)^{\mathrm{a}} 2.9(0.2)^{\mathrm{c}}$ & $0.80(0.02)^{\mathrm{a}} 20.6(0.2)^{\mathrm{a}}$ \\
\hline TNFCPPG0 & $0.82(0.05)^{\mathrm{b}} 11.7(0.2)^{\mathrm{a}} 0.62(0.06)^{\mathrm{b}}$ & $8.8(0.5)^{\mathrm{b}}$ \\
\hline TNFCPPG5 & $0.79(0.03)^{\mathrm{b}}$ & $8.7(0.2)^{\mathrm{b}}$ & $0.58(0.03)^{\mathrm{b}}$ & $7.6(0.3)^{\mathrm{c}}$ \\
\hline TNFCPPG10 & $0.81(0.02)^{\mathrm{b}} 12.0(0.2)^{\mathrm{a}} 0.37(0.02)^{\mathrm{c}}$ & $6.5(0.4)^{\mathrm{d}}$ \\
\hline
\end{tabular}

Means with different letters in the same column indicate significant differences $(p<0.05)$.

A good quality pasta product should present certain degrees of firmness and elasticity, absence of stickiness, appearance uniformity and structural integrity. As expected, the firmness of GF formulations was significantly lower than that of control pasta (Table3), decreasing with higher contents of PG (although variations were small for this parameter). Although the use of PG at 5 or $10 \%$ did not imply an improvement on the firmness of cooked pasta, it did provide some continuity to the pasta structure (Figure 1). 


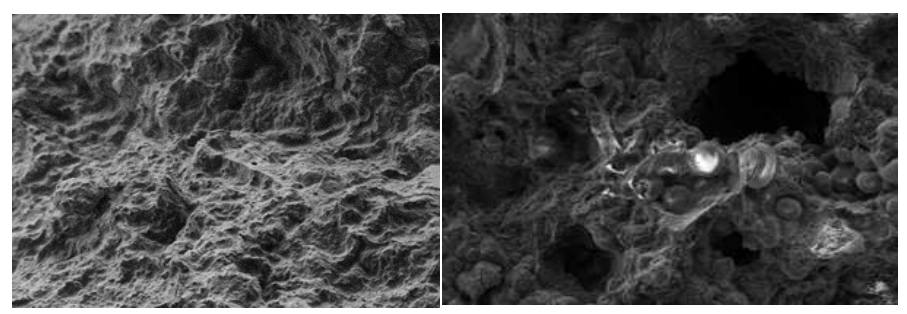

Fig. 1 FESEM dry pasta TNFCPPG0 and TNFCPPG10 (500x).

\section{Conclusions}

The consumption of gluten free pappardelle formulated with tiger nut and chickpea flours can have positive implications for human health, due to their increased nutritional quality. Cooking losses were acceptable and a certain structural continuity was obtained when pregelatinized tiger nut flour was used, thus further investigations are required.

\section{References}

[1] Lamacchia, C.; Camarca, A.; Picascia, S.; Di Luccia, A.; Ginafrani, C. Cereal based gluten-free food: How to reconcile nutritional and technological properties of wheat proteins with safety for celiac disease patients. Nutrients 2014, 6, 575-590.

[2] O'Shea, N.; Arendt, E.; Gallagher, E. State of the art of gluten-free research. Journal of Food Science, 2014, 79, 1067-1076.

[3] Foster-Powell, K.; Holt, S.H.A.; Brand-Miller, J.C. International table of glycemic index and glycemic load values: 2002. The American Journal of Clinical Nutrition, 2002, 76, 5-56.

[4] Marti, A.; Pagani, M.A. What can play the role of gluten free pasta? Trends in Food Science \& Technology, 2013, 31, 63-71.

[5] Larrosa, V; Lorenzo, G.; Zaritzky, N.; Califano, A. Optimization of rheological properties of gluten-free pasta dough using mixture design. Journal of Cereal Science, 2013, 57(3), 520-526.

[6] Marti, A.; Caramanico, R.; Bottega, G.; Pagani, M.A. Cooking behavior of rice pasta: Effect of thermal treatments and extrusion conditions. Food Science and Technology, 2013, 54, 229-235.

[7] Fiorda, F.A.; Soares Jr. M.S.; da Silva, F.A.; Grosmann, M.V.E.; Souto, L.R.V. Microestructure, texture and colour of gluten-free pasta made with amaranth flour, cassava starch and cassava bagasse. Food Science and Technology, 2013, 54, 132-138.

[8] Fu, B.X. Asian noodles: history, classification, raw materials, and processing. Food Research International, 2008, 41, 888-902.

[9] AACC. Approved methods of the AACC (10th ed). St. Paul, MN, USA: American Association of Cereal Chemists. 2000.

[10] Heywood, A.A., Myers, D.J.; Bailey, T.B., Johnson, L.A. Functional properties of low-fat soy flour produced by an extrusion expelling system. American Oil 
Cheminstry Society, 2002, 79, 1249-1253.

[11] Lin C.S; Zayas J.F. Functionality of defatted corn germ proteins in a model system: fat binding capacity and water retention. Food Science, 1987, 52, 1308-1311.

[12] Ahn, H.J.;Kim, J.H., Ng, P.K.W. Functional and thermal properties of wheat, barley, and soy flours and their blends treated with a microbial transglutaminase. Journal Food Science, 2005, 70, 380-386.

[13] Albors, A.; Raigon, M. D.; García-Martinez, M. D.; Martín-Esparza, M. E. 2016. Assessment of techno-functional and sensory attributes of tiger nut fresh egg tagliatelle. LWT-Food Science and Technology, 2016, 74, 183-190.

[14] Gull, A.; Prasad, K.; Kumar, P. Effect of millet flours and carrot pomace on cooking qualities, color and texture of developed pasta. LWT-Food Science and Technology, 2015, 63(1), 470-474.

[15] Mestres, C.; Colonna, P.; Alexandre, M.C.; Matencio, F. Comparison of various processes for making maize pasta. Journal of Cereal Science, 1993, 17, 277-290.

[16] Giuberti, G.; Gallo, A.; Cerioli, C.; Fortunati, P.; Masoero, F. 2015. Cooking quality and starch digestibility of gluten free pasta using new bean flour. Food Chemistry, 175: 43-49

[17] Caperuto, L.C.; Amaya-Farfan, J.; Camargo, C.R.O. Performance of quinoa (Chenopodium quinoa Willd) flour in the manufacture of gluten free spaghetti. Journal of the Science of Food and Agriculture, 2000, 81, 95-101. 